\title{
Synthesis of some glucose-fatty acid esters by lipase from Candida antarctica and their emulsion functions
}

\author{
Kangzi Ren, Buddhi P Lamsal* \\ Department of Food Science and Human Nutrition, Iowa State University. \\ 2312 Food Science Building, Iowa State University, Ames, IA 50010, USA. \\ * Corresponding author: \\ Department of Food Science and Human Nutrition, Iowa State University \\ 2312 Science Building, Iowa State University, Ames, IA 20010, USA \\ lamsal@iastate.edu; +1 (515) 294-8681
}




\begin{abstract}
The synthesis of glucose esters with palmitic acid, lauric acid and hexanoic acid using lipase enzyme were studied and their emulsion functionality in oil-in-water system were compared. Reactions at 3:1 molar ratio of fatty acids-to-glucose had the highest conversion percentages (over $90 \%$ for each of the fatty acid). Initial conversion rate increased as substrate solubility increased. Ester bond formation was confirmed by nuclear magnetic resonance technique that the chemical shifts of glucose $\mathrm{H}-6$ and $\alpha$-carbon protons of fatty acids in the ester molecules shifted to the higher fields. Contact angle of water on esters' pelleted surface increased as the hydrophobicity increased. Glucose esters' and commercial sucrose esters' functionality as emulsifiers were compared. Glucose esters delayed, but did not prevent coalescence, because the oil droplets diameter doubled during 7 days. Sucrose esters prevented coalescence during 7 days since the droplets diameter did not have significant change.
\end{abstract}

Key words: glucose ester; synthesis; lipase; contact angle; emulsifier; sucrose ester.

\title{
1. Introduction
}

Surfactants are amphiphilic molecules with both hydrophilic and hydrophobic moieties that can adsorb at the interface between phases with different polarities and reduce interfacial tension. Thus, they have functionality in detergency, emulsifying, dispersion, foaming industry (Greek, 1991, 1990). Traditional surfactants are mainly derived from petroleum industry products, which requires unfavorable reaction conditions such as high temperature, high acidity, alkalinity, organic solvent, and they have low biodegradability and high aquatic toxicity (Deleu \& Paquot, 2004). However, surfactants can also be produced via enzymatic reactions or microbial fermentation utilizing biological feedstocks. These environmentally compatible surfactants, also called biobased surfactants, are biodegradable. Some of the microorganisms that 
produce surfactants during fermentation are Pseudomonas, Rhodococcus, Mycobacterium, Toruplopsis, Bacillus, Thiobacillus, etc (Desai \& Banat, 1997). The surfactants derived from microorganisms are glycolipid, lipopeptides, lipoproteins, fatty acids and phospholipids, etc (Desai \& Bannat 1997). In enzyme-catalyzed production of biobased surfactants, the common enzymes utilized are lipase, proteinase and glucosidase (Hayes, 2011). Lipase catalyzes ester bond formation between fatty acyl groups and hydroxyl group of alcohols or polyols; amino acid also can act as acyl donor and form ester or amide bond if proteinase are used; glycosidases catalyze the acetal bond formation between saccharides and fatty alcohols (Van Rantwijk, Woudenberg-van Oosterom, \& Sheldon, 1999). Lipase-catalyzed reactions were studied in terms of reaction solvent, substrate ratio, reaction time etc. Commonly used acyl acceptors are carbohydrate, sugar alcohol. Acyl donors are various fatty acids or fatty acid esters. Enzymatic synthesis have the advantages of higher selectivity, relatively lower temperatures (lower than 70 ${ }^{\circ} \mathrm{C}$ ), lower solvent toxicity, and easier separation of products compared to traditional chemical synthesis. Enzyme that have been used for synthesis of esters are subtilisin from Bacillus amyloliquefaciens (Rich, Bedell, \& Dordick, 1995), lipase from Candida antarctica (Pedersen, Wimmer, Emmersen, Degn, \& Pedersen, 2002), Candida rugosa (Zaidan, Abdul Rahman, Othman, Basri, Abdulmalek, Abdul Rahman, et al., 2012) Mucor miehei (Degn, Pedersen, \& Zimmermann, 1999), Humicola lanuginose (Ferrer, Cruces, Bernabe, Ballesteros, \& Plou, 1999), Thermomyces lanuginosus (Tsavas, Polydorou, Faflia, Voutsas, Tassios, Flores, et al., 2002), and alkaline protease from Streptomyces spp (Kitagawa, Tokiwa, Fan, Raku, \& Tokiwa, 2000). Sugar- fatty acid esters are non-ionic surfactants with a wide range of hydrophilic-lipophilic balance (HLB) values. Since they are biodegradable, non-toxic (Ferrer, Cruces, Bernabe, Ballesteros, \& Plou, 1999), non-irritant to skin (Plat \& Linhardt, 2001) and odorless, they are 
widely used in food, pharmaceutical, cosmetic and detergent industries. Sucrose esters have been approved by Food and Drug Administration and are widely used in food industry, such as wheat products, confectioneries, and dairy products, etc. The functions are various, such as increasing dough resistance to kneading, increasing cake volume, prevent stickiness to the machine, make stable emulsion, improve mouthfeel, prevent staling, etc. (Mitsubishi-Kagaku Food Corporation, http://www.mfc.co.jp/english/infor.htm).

The challenge to synthesize sugar-fatty acid ester enzymatically is to find good solvent(s) to solubilize the substrates that have different polarities, at the meantime, not deactivating enzymes. It has been extensively studied in different medium, for example, single phase organic solvent systems (Degn, Pedersen, \& Zimmermann, 1999; Ljunger, Adlercreutz, \& Mattiasson, 1994;), two organic solvent systems (Kitagawa, Tokiwa, Fan, Raku, \& Tokiwa, 2000; ReyesDuarte, López-Cortés, Ferrer, Plou, \& Ballesteros, 2005), non-solvent systems (Martin-Arjol, Isbell, \& Manresa, 2015), ionic liquid systems, supercritical carbon dioxide (Habulin, Šabeder, \& Knez, 2008) and deep eutectic systems (Pohnlein, Ulrich, Kirschhofer, Nusser, Muhle-Goll, Kannengiesser, et al., 2015). Mixed organic solvents were preferred than single solvent since by varying the ratio of each solvent, solubility of acyl acceptor and enzyme activity can be controlled. To avoid the use of organic solvent and improve miscibility, solvent-free systems were used (Fregapane, Sarney, \& Vulfson, 1991; Ward, Fang, \& Li, 1997). However, the reaction system had high viscosity and low miscibility (Wei, Yu, Song, \& Su, 2003). Ionic solvents were used because of their advantage of low vapor pressures and tunable chemical structure that can solubilize different substrates (Park \& Kazlauskas, 2001) while they have disadvantage of extra steps to synthesize and purify of ionic solvents, and some ionic liquid were reported to deactivate the enzyme (Schöfer, Kaftzik, Wasserscheid, \& Kragl, 2001). Dimethyl 
sulfoxide (DMSO) and 2-methyl-2-butanol (2M2B) were chosen as reaction media to synthesize glucose esters due to relatively high solubility of sugar and fatty acids and being benign to enzymes.

Although the synthesis of sugar fatty acid esters has been studied extensively, their functionality as emulsifiers in the basic oil-in-water system has not been looked in-depth. Glucose is a cheap carbohydrate with only one primary hydroxyl group, therefore, the high selectivity is expected. Also, not many research (Arcos, Bernabe, \& Otero, 1998; Degn, Pedersen, \& Zimmermann, 1999; Ljunger, Adlercreutz, \& Mattiasson, 1994) studied the synthesis condition and their functionalities. The objectives of this study are to: 1) optimize the synthesis of glucose esters with respect to substrate ratio and fatty acid types, and 2) evaluate the functionality of glucose esters as emulsifiers and compare with commercial sucrose esters that have different HLB values.

\section{Materials and Methods}

\subsection{Reagents}

DMSO, 2M2B, D-glucose, HPLC-grade methanol, and molecular sieves (3Å) were purchased from Fisher Scientific (Fair Lawn, NJ). Palmitic acid (98\%), lauric acid (>98\%), hexanoic acid (>99.5\%), and immobilized lipase from Candida Antarctica were purchased from Sigma-Aldrich (St. Louis, MO). Pure canola oil was purchased from a local grocery store. Commercial sucrose esters SP30 (sucrose distearate, HLB 6, monoester content 30\%), SP50 (sucrose stearate, HLB 11, monoester content 50\%), PS750 (sucrose palmitate, HLB 16, monoester content $75 \%$ ) were donated.

\subsection{Synthesis of glucose esters}


The lipase-catalyzed synthesis of glucose esters was carried out in 50-mL Erlenmeyer flasks following published method with some modifications (Ferrer, Cruces, Bernabe, Ballesteros, \& Plou, 1999). Palmitic acid, lauric acid, and hexanoic acid were used as acyl donor and glucose was used as acyl acceptor for esterification reactions. Molar ratios of fatty acid and sugar were $0.3 \mathrm{mM}: 0.1 \mathrm{mM}, 0.2 \mathrm{mM}: 0.1 \mathrm{mM}, 0.1 \mathrm{mM}: 0.1 \mathrm{mM}$, and $0.1 \mathrm{mM}: 0.3 \mathrm{mM}$. One g molecular sieves and $0.25 \mathrm{~g}$ immobilized lipases were added in $10 \mathrm{~mL}$ solvent mix (80\% DMSO and 20\% 2M2B). The flasks were incubated at $55{ }^{\circ} \mathrm{C}$ in a water bath with shaking at $96 \mathrm{rpm}$ for $48 \mathrm{~h}$.

After $48 \mathrm{~h}$ of reaction, reactants were centrifuged to obtain the supernatants. Supernatants were placed under a fume hood overnight to evaporate 2M2B. Water (approximately 10:1 v/v of solvent) was added to the medium to precipitate the fatty acid residue and esters. The viscous white slurry was filtered to obtain white solid. The solids were washed with 10 volumes of methanol for 3-4 times to dissolve free fatty acid residue and obtain highly pure esters. The purity of glucose esters was determined with NMR 1D proton test to obtain the area ratio of proton of $\alpha$ carbon $\left(-\mathrm{CH}_{2}-\mathrm{COOH}\right)$ of bonded fatty acid and free fatty acid.

\subsection{Quantitation of fatty acid conversion}

The quantitation of fatty acids by HPLC method followed a previous study (ReyesDuarte, López-Cortés, Ferrer, Plou, \& Ballesteros, 2005) with slight modification. At $0,3^{\text {rd }}$, $6^{\text {th }}$, $12^{\text {th }}, 24^{\text {th }}, 36^{\text {th }}$ and $48^{\text {th }} \mathrm{h}$, aliquots of reactant mix were withdrawn and measured for residual free fatty acid by high performance liquid chromatography (Thermo Scientific, ACCELA 1250 HPLC) using a C18 column (Hypersil Gold, 50×2.1 mm, $1.9 \mu \mathrm{m}$ ), a PDA detector (at $200 \mathrm{~nm}$ ), and EZChrom Elite software (Agilent, Version3.2.1). For palmitate acid detection, methanol: water 70/30 (v/v) with $0.1 \% \mathrm{v} / \mathrm{v}$ acetic acid was used as mobile phase A for the first $2 \mathrm{~min}$, then 
a gradient from this eluent to pure methanol (B) was continued for $5 \mathrm{~min}$, after which the gradient was changed back to the mobile phase A for $5 \mathrm{~min}$. The flow rate was $0.5 \mathrm{~mL} / \mathrm{min}$ and the temperature was $45^{\circ} \mathrm{C}$. The method to detect lauric acid was the same as it was for palmitic acid. For hexanoic acid detection, the mobile phase A was methanol: water 80/20 (v/v) with $0.1 \%$ acetic acid for $4 \mathrm{~min}$, then a gradient to pure methanol was last for $5 \mathrm{~min}$, then it changed back to A. The flow rate of mobile phase was $0.5 \mathrm{~mL} / \mathrm{min}$ for all fatty acids. The conversion of fatty acid was calculated as:

Conversion of fatty acid $=\left(\mathrm{X}_{0}-\mathrm{X}_{1}\right) / \mathrm{X}_{0}, \times 100 \%$

$\mathrm{X}_{0}$ - fatty acid concentration at the start of reaction

$\mathrm{X}_{1}$-residual fatty acid concentration in reaction mix at different time points.

$\mathrm{X}_{0}$ - theoretical concentration of fatty acid that can be fully converted to ester.

From stoichiometry of reaction systems, $X_{0}$, is the $1 / 3$ of initial concentration at $3: 1$ acid: sugar ratio, and 1/2 of initial concentration for $2: 1$ ratio.

\subsection{Identification of esters}

Agilent Quadrupole Time-of-Flight (QTOF) 6540 liquid chromatography mass spectrometry (LC/MS) was used to identify reaction products. A XDB C18 column $(4.6 \times 50 \mathrm{~mm}$, $1.8 \mu \mathrm{m})$ and an electrospray ionization detector were used. The products were scanned in the negative mode from 100-1000 Daltons. A gradient from 95\% mobile phase A (water, 100\%) and 5\% B (methanol, 100\%) to 95\% B and 5\% A was applied for 20 min and kept for another 5 min. The flow rate of mobile phase was $0.8 \mathrm{~mL} / \mathrm{min}$. Nuclear magnetic resonance (NMR) (Bruker Avance III 600, Billerica, MA and Karlsruhe, Germany) was used to confirm the formation of ester bonds and chemical shifts of important carbon and hydrogen atoms. The products were dissolved in deuterated DMSO to achieve a concentration range of 50-800 $\mathrm{mg} / \mathrm{mL}$. 
Heteronuclear single quantum coherence (HSQC) and heteronuclear multiple bond correlation (HMBC) spectroscopy for $1 \mathrm{H}$ and $13 \mathrm{C}$ were used to determine the ester bond formation. The data were analyzed with the TopSpin software (Bruker, Billerica, MA).

Chemical shifts, splitting patterns, J-coupling and positions of hydrogen and carbon for reactants and products are as follows:

Glucose, the spectrum showed it was a mixture of $\alpha$ - and $\beta$-anomers. ${ }^{1} \mathrm{H}$ NMR $(600 \mathrm{MHz}$, DMSO- $\left.d_{6}\right) \delta 4.91(\mathrm{t}, J=4.2 \mathrm{~Hz}, 1 \mathrm{H}, \mathrm{H}-1), 3.42(\mathrm{dt}, J=9.1,4.3 \mathrm{~Hz}, 1 \mathrm{H}, \mathrm{H}-2), 3.11$ (ddd, $J=$ 10.0, 6.7, 3.6 Hz, 1H, H-3), 3.04 (td, $J=9.3,5.4 \mathrm{~Hz}, 1 \mathrm{H}, \mathrm{H}-4), 3.58-3.52$ (m, 1H, H-5), $3.48-$ $3.44(\mathrm{~m}, 1 \mathrm{H}, \mathrm{H}-6 \mathrm{a}), 3.60(\mathrm{dd}, J=11.5,5.9 \mathrm{~Hz}, 1 \mathrm{H}, \mathrm{H}-6 \mathrm{~b}) .{ }^{13} \mathrm{C}$ NMR $\left(151 \mathrm{MHz}, \mathrm{DMSO}-d_{6}\right) \delta$ 92.67 (C-1), 72.809 (C-2), 73.541 (C-3), 71.03 (C-4), 72.403 (C-5), 61.676 (C-6).

Palmitic acid. ${ }^{1} \mathrm{H}$ NMR (600 MHz, DMSO- $\left.d_{6}\right) \delta 11.93(\mathrm{~s}, 1 \mathrm{H},-\mathrm{COOH}), 2.166$ (t, $J=7.5$ $\left.\mathrm{Hz}, 2 \mathrm{H},-\mathrm{CH}_{2} \mathrm{CO}-\right), 1.486$ (t, $\left.J=7.2 \mathrm{~Hz}, 2 \mathrm{H},-\mathrm{CH}_{2}-\mathrm{CH}_{2}-\mathrm{CO}-\right), 1.205-1.294$ (s, 24H, chain), 0.853 $\left(\mathrm{m}, 3 \mathrm{H},-\mathrm{CH}_{3}\right) .{ }^{13} \mathrm{C}$ NMR $\left(151 \mathrm{MHz}, \mathrm{DMSO}-d_{6}\right) \delta 174.75(\mathrm{C}=\mathrm{O}), 34.119\left(-\mathrm{CH}_{2}-\mathrm{CO}-\right), 31.87(-$ $\left.\mathrm{CH}_{2}-\mathrm{CH}_{2}-\mathrm{CO}-\right)$, 29.661-29.661, 29.31, 29.16, 24.997, 22.617 (- $\mathrm{CH}_{2}$ - palmitic acid backbone), $14.263\left(-\mathrm{CH}_{3}\right)$.

Lauric acid. ${ }^{1} \mathrm{H}$ NMR (600 MHz, DMSO- $\left.d_{6}\right) \delta 11.95(\mathrm{~s}, 1 \mathrm{H},-\mathrm{COOH}), 2.176(\mathrm{t}, J=7.5$ $\mathrm{Hz}, 2 \mathrm{H},-\mathrm{CH}_{2} \mathrm{CO}-$ ), 1.495 (t, $J=7.4 \mathrm{~Hz}, 2 \mathrm{H},-\mathrm{CH}_{2}-\mathrm{CH}_{2}-\mathrm{CO}-$ ), $1.244-1.297$ (s, 16H, chain), 0.86 $\left(\mathrm{d}, J=7.5 \mathrm{~Hz}, 3 \mathrm{H},-\mathrm{CH}_{3}\right) .{ }^{13} \mathrm{C}$ NMR $\left(151 \mathrm{MHz}, \mathrm{DMSO}-d_{6}\right) \delta 174.85(\mathrm{C}=\mathrm{O}), 34.12\left(-\mathrm{CH}_{2}-\mathrm{CO}-\right)$, $31.816,29.541,29.528,29.449,29.285,29.243,29.079,24.979,22.597\left(-\mathrm{CH}_{2}\right.$ - lauric acid backbone), $14.344\left(-\mathrm{CH}_{3}\right)$. 
Hexanoic acid. ${ }^{1} \mathrm{H}$ NMR $\left(600 \mathrm{MHz}, \mathrm{DMSO}-d_{6}\right) \delta 11.889(\mathrm{~s}, 1 \mathrm{H},-\mathrm{COOH}), 2.172(\mathrm{t}, J=$ $\left.7.6 \mathrm{~Hz}, 2 \mathrm{H},-\mathrm{CH}_{2} \mathrm{CO}-\right), 1.502-1.264\left(6 \mathrm{H}\right.$, chain), 0.859 (t, $\left.J=7.1 \mathrm{~Hz}, 3 \mathrm{H},-\mathrm{CH}_{3}\right) .{ }^{13} \mathrm{C} \mathrm{NMR}(151$ MHz, DMSO- $\left.d_{6}\right) \delta 174.86(\mathrm{C}=\mathrm{O}), 34.05\left(-\mathrm{CH}_{2}-\mathrm{CO}-\right), 31.25,24.64,22.31\left(-\mathrm{CH}_{2}-\right.$ hexanoic acid backbone), $14.16\left(-\mathrm{CH}_{3}\right)$.

6-O-Palmitoylglucopyranose. ${ }^{1} \mathrm{H}$ NMR $\left(600 \mathrm{MHz}, \mathrm{DMSO}-d_{6}\right) \delta 4.91(\mathrm{t}, J=4.4 \mathrm{~Hz}, 1 \mathrm{H}$, H-1), 3.137 (m, 1H, H-2), 3.44 (td, $J=9.1,4.5 \mathrm{~Hz}, 1 \mathrm{H}, \mathrm{H}-3), 3.042$ (td, $J=9.3,5.5 \mathrm{~Hz}, 1 \mathrm{H}, \mathrm{H}-$ 4), $3.78(\mathrm{dd}, J=9.5,6.5 \mathrm{~Hz}, 1 \mathrm{H}, \mathrm{H}-5), 4.28$ (d, $J=11.5 \mathrm{~Hz}, 1 \mathrm{H}, \mathrm{H}-6 \mathrm{a}), 4.00$ (dd, $J=11.7,6.2$ $\mathrm{Hz}, 1 \mathrm{H}, \mathrm{H}-6 \mathrm{~b}), 2.28$ (t, $\left.J=7.4 \mathrm{~Hz}, 2 \mathrm{H},-\mathrm{CH}_{2}-\mathrm{CO}-\right), 1.51$ (q, $J=7.2 \mathrm{~Hz}, 2 \mathrm{H},-\mathrm{CH}_{2}-\mathrm{CH}_{2}-\mathrm{CO}-$ ), 1.25 (s, 24H, chain), $0.87\left(\mathrm{t}, J=6.9 \mathrm{~Hz}, 3 \mathrm{H},-\mathrm{CH}_{3}\right) .{ }^{13} \mathrm{C}$ NMR $\left(151 \mathrm{MHz}, \mathrm{DMSO}-d_{6}\right) \delta 92.755$ (C-1), 72.66 (C-2), 73.336 (C-3), 71.035 (C-4), 69.601 (C-5), 64.355 (C-6), 173.363 (C=O), 33.906 (- $\left.\mathrm{CH}_{2}-\mathrm{CO}-\right), 31.778$ (- $\left.\mathrm{CH}_{2}-\mathrm{CH}_{2}-\mathrm{CO}-\right), 29.534-28.931,24.94,22.569$ (- $\mathrm{CH}_{2}$ - palmitoyl backbone), $14.341\left(-\mathrm{CH}_{3}\right)$.

6- $\boldsymbol{O}$-Lauroylglucopyranose. ${ }^{1} \mathrm{H}$ NMR $\left(600 \mathrm{MHz}, \mathrm{DMSO}-d_{6}\right) \delta 4.909$ (d, $J=4.7 \mathrm{~Hz}, 1 \mathrm{H}$, H-1), 3.137 (m, 1H, H-2), 3.439 (td, $J=9.2,4.3 \mathrm{~Hz}, 1 \mathrm{H}, \mathrm{H}-3), 3.043$ (m, 1H, H-4), 3.774 (dd, $J$ = 9.7, $6.8 \mathrm{~Hz}, 1 \mathrm{H}, \mathrm{H}-5), 4.277(\mathrm{~d}, J=11.9 \mathrm{~Hz}, 1 \mathrm{H}, \mathrm{H}-6 \mathrm{a}), 4.006(\mathrm{dd}, J=11.7,6.2 \mathrm{~Hz}, 1 \mathrm{H}, \mathrm{H}-$ 6b), 2.28 (t, $\left.J=7.3 \mathrm{~Hz}, 2 \mathrm{H},-\mathrm{CH}_{2}-\mathrm{CO}-\right), 1.52$ (t, $\left.J=7.1 \mathrm{~Hz}, 2 \mathrm{H},-\mathrm{CH}_{2}-\mathrm{CH}_{2}-\mathrm{CO}-\right), 1.25$ (s, $16 \mathrm{H}$, chain), 0.87 (t, $\left.J=6.8 \mathrm{~Hz}, 3 \mathrm{H},-\mathrm{CH}_{3}\right) .{ }^{13} \mathrm{C}$ NMR (151 MHz, DMSO- $\left.d_{6}\right) \delta 92.754(\mathrm{C}-1), 72.659$ (C-2), $73.334(\mathrm{C}-3), 71.027(\mathrm{C}-4), 69.602(\mathrm{C}-5), 64.362(\mathrm{C}-6), 173.272(\mathrm{C}=\mathrm{O}), 33.909\left(-\mathrm{CH}_{2}-\right.$ CO-) , 31.814 , 29.541 , 29.526 , 29.434, 29.268, 29.24, 28.964, 24.94, 22.592 (- $\mathrm{CH}_{2}$ - lauroyl backbone), $14.42\left(-\mathrm{CH}_{3}\right)$. 


\section{6-O-Hexanoylglucopyranose}

${ }^{1} \mathrm{H}$ NMR (600 MHz, DMSO-d6) $\delta 4.911$ (d, $J=3.9$ Hz, 1H, H-1), 3.132 (m, 1H, H-2), 3.43 (m, 1H, H-3), 3.055 (dd, $J=17.2,7.4$ Hz, 1H, H-4), 3.771 (s, 1H, H-5), 4.29 (dd, $J=19.7$, 11.6 Hz, 1H, H-6a), 3.997 (m, 1H, H-6b), 2.293, 1.51 (dt, $J=14.7,7.9 \mathrm{~Hz}, 2 \mathrm{H},-\mathrm{CH}_{2}-\mathrm{CO}-$ ), 1.576-1.191 (m, 6H, caproyl backbone), $0.873\left(\mathrm{~d}, J=8.3 \mathrm{~Hz}, 3 \mathrm{H},-\mathrm{CH}_{3}\right) .{ }^{13} \mathrm{C} \mathrm{NMR}(151 \mathrm{MHz}$, DMSO- $\left.d_{6}\right) \delta 173.444(\mathrm{C}=\mathrm{O}), 34.177\left(-\mathrm{CH}_{2}-\mathrm{CO}-\right), 31.097,24.643,22.287\left(-\mathrm{CH}_{2}-\right.$ hexanoyl backcone).

\subsection{Initial sugar solubility}

Initial sugar solubility of ester was tested by HPLC method. After mixing reactants except lipase in the solvents as described in synthesis method above, flasks were incubated in the water bath at $55^{\circ} \mathrm{C}$ at $3.8 \mathrm{rpm}$ for $30 \mathrm{~min}$. After cooling down, aliquots from each flask were run through HPLC. A carbohydrate column (HyperRez XP Carbohydrate H+, 300×7.7 mm, $8 \mu \mathrm{m}$ ), a guard column (HyperRez XP Carbohydrate H+, 50×7.7 mm, $8 \mu \mathrm{m}$ ) and a RI detector were used The temperature for guard column and carbohydrate column were $65{ }^{\circ} \mathrm{C}$ and $70{ }^{\circ} \mathrm{C}$, the flow rate was $0.4 \mathrm{~mL} / \mathrm{min}$.

\subsection{Emulsion stability Index}

$0.01 \% \mathrm{w} / \mathrm{w}, 0.1 \% \mathrm{w} / \mathrm{w}$ and $0.5 \% \mathrm{w} / \mathrm{w} 100 \mathrm{~g}$ ester solutions were prepared and mixed with $10 \mathrm{~g}$ canola oil, control treatment did not contain any esters. The mixtures were sonicated for $10 \mathrm{~min}$ to improve ester dispersion. The mixture was then homogenized for $2 \mathrm{~min}$ at 15,000 rpm using a blender (Bamix Type M 150) and $10 \mu \mathrm{L}-20 \mu \mathrm{L}$ aliquots of emulsion were diluted with 2 $\mathrm{mL}$ deionized water in the spectrophotometer cuvette. Absorbance of emulsion at $500 \mathrm{~nm}$ was measured at 0 , and 20 min. The emulsion stability index (ESI) was calculated as: 
$\mathrm{ESI}=\mathrm{A}_{0} * 20 /\left[\mathrm{A}_{0}-\mathrm{A}_{20}\right] . \mathrm{A}_{0}$ and $\mathrm{A}_{20}$ were the absorbance obtained at $0 \mathrm{~min}$ and $20 \mathrm{~min}$ (Pearce \& Kinsella, 1978). The higher ESI values indicated higher emulsion stability.

\subsection{Emulsion droplet size distribution}

The emulsion droplet size distribution was measured by Malvern Particle Size analyzer (Mastersizer Hydro 2000). Emulsions with $0.5 \% \mathrm{w} / \mathrm{w}$ level of esters were prepared as above and were introduced into the instrument until a laser obscuration of 10-20\% was achieved.

Measurements were taken at time $0 \mathrm{~h}, 6^{\text {th }} \mathrm{h}, 24^{\text {th }} \mathrm{h}, 3^{\text {rd }} \mathrm{d}$ and $7^{\text {th }} \mathrm{d}$.

\subsection{Contact angle measurement}

Contact angle measurement followed a previous research (Crowley, Desautel, Gazi, Kelly, Huppertz, \& O’Mahony, 2015). Pellets of each of the esters were prepared with 0.08g powdered ester, placing them on a $13 \mathrm{~mm}$ pellet die and pressing under a force of $5000 \mathrm{~kg}$ for 2 min in Carver Press (model 3619, Carver Inc, Wabash, IN). Contact angle measurement was conducted using a goniometer (Rame-Hart Model 250 Standard Goniometer). Approximately 4 $\mu \mathrm{L}$ water droplet was dispensed on the pellet's surface placed on a stage. Side view pictures were taken immediately after the water droplet left the syringe tip using a high-resolution camera.

\subsection{Statistical analysis}

Statistic test was conducted using SAS 9.4 software (SAS Institute Inc., Cary, NC). Proc GLIMMIX test was used to determine significant difference between treatments $(\mathrm{P}<0.05)$. At least three observations for each treatment were measured for conversion, sugar solubility, contact angle, emulsion stability and droplet size analysis.

\section{Results and Discussion}

\subsection{Fatty acid conversion}


Figure 1 (a), (b) and (c) show the conversion percentages of palmitic acid, lauric acid and hexanoic acid over $48 \mathrm{~h}$, respectively. The fatty acid/glucose molar ratios were compared for optimum ratio for the highest conversion. For each glucose-fatty acid ester studied, the highest conversion of fatty acid was achieved when the ratio was $3: 1(97.17 \%, 76.57 \%, 113.11 \%$ for glucose palmitate, laurate and hexanoate, respectively). The second highest conversions were at the ratio of $2: 1(75.96 \%, 62.82 \%, 73.66 \%$, respectively). The $1: 1$ and $1: 3$ ratios did not have any significantly differences; the conversion was around $50 \%, 40 \%, 30 \%$, respectively for palmitic acid, lauric acid and hexanoic acid. Higher concentrations of FA favored formation of the products as explained by the equilibrium constant:

$$
\begin{array}{ll}
\mathrm{k}=[\text { ester] }[\text { water }] /[\text { fatty acid][glucose }] & \text { (Equation } 1) \\
\text { or, }[\text { ester }]=\mathrm{k} \times[\text { fatty acid] }[\text { glucose]/[water }] & \text { (Equation } 2) \text {. }
\end{array}
$$

At a given temperature $\left(55^{\circ} \mathrm{C}\right.$ in this study $), \mathrm{k}$ is a constant. At higher molar ratios of fatty acid to glucose $(2: 1$ or $3: 1)$, the limiting reactant is glucose, thus, only $1 / 3^{\text {rd }}$ of available fatty acid is converted to ester and water. Therefore, the increase in fatty acid concentration in reaction mix would be larger than the increase in water amount. Meanwhile, the glucose concentration remained at a similar level compared to the reaction when the ratio was $1: 1$. Therefore, the increase of fatty acids amount increased the ester amount according to Equation 2, as reflected by the conversion percentage. For the reactants ratio of $1: 1$ and $1: 3$ of fatty acid to glucose, glucose solubility was limited in the medium as glucose crystals could be seen throughout the reaction, and fatty acid were completely dissolved. For these conditions, terms in Equation 2 did not have significant changes, indicating similar conversions for these two ratios. Among various fatty acids, the hexanoic acid had the highest conversion percentage at 3:1 ratio (113\%). This could be due to the formation of diesters, along with monoesters, but at low levels 
since they were not detected by LCMS and NMR. Two reasons could contribute to the higher conversion of hexanoic acid: shorter carbon chains making the solvent more polar resulting in higher glucose solubility (data will be shown in later section) than other two fatty acids, and possible less stearic hindrance than palmitic acid and lauric acid- the smaller molecule would have easier access to enzyme active sites and result in higher level of esterification.

\subsection{Initial substrate concentration and initial conversion rates}

Influence of reactant concentrations on the initial conversion rates (linear range for first three hours) is presented in Table 1. For the molar ratios of 3:1, 2:1, 1:1 (fatty acid/glucose) in esterification of palmitic acid and lauric acid, fatty acids were completely soluble in solvent, so, the fatty acids concentration increased as molar ratio increased, which led to higher initial fatty acid conversion rates. For molar ratio increase from 1:1 to 3:1 (fatty acid concentration increase from $74.3 \mathrm{mM}$ to $243.7 \mathrm{mM}$ ), the initial conversion rates also increased threefold from 3.3 $\mu \mathrm{mol} /(\min \cdot \mathrm{g})$ to $9.6 \mu \mathrm{mol} /(\mathrm{min} \cdot \mathrm{g})$. Glucose did not completely solubilize for these molar ratios of 1:1 and 1:3 (fatty acid/glucose), because sugar crystals were seen in the medium, thus we examined the soluble glucose concentration. For fatty acid: glucose molar ratios of 1:1 and 1:3 with increase in glucose concentration from $21 \mathrm{mM}$ to $28.2 \mathrm{mM}$, the initial conversion rates increased from $3.3 \mu \mathrm{mol} /(\mathrm{min} \cdot \mathrm{g})$ to $5.2 \mu \mathrm{mol} /(\mathrm{min} \cdot \mathrm{g})$. Therefore, it is obviously seen that the concentration of both fatty acid and glucose had direct and proportional relationship with the initial conversion rate, indicating the reaction to be a first-order reaction in terms of either fatty acid or glucose (Degn \& Zimmermann, 2001). For hexanoic acid, the increase of fatty acid concentration from $146.5 \mathrm{mM}$ to $235.2 \mathrm{mM}$ almost quadrupled the rate (Table 1), and the glucose solubility did not change over the three ratios and did not affect the initial rate. The highest conversion rate obtained was $11.83 \mu \mathrm{mol} /(\mathrm{min} \cdot \mathrm{g})$, which is similar to reported 15.2 
$\mu \mathrm{mol} /(\mathrm{min} \cdot \mathrm{g})$ for synthesis of glucose myristate (Degn \& Zimmermann, 2001) that was conducted in t-butanol: pyridine system. Although the glucose solubility was higher in our system, the deactivation of lipase in DMSO is stronger than pyridine. They also reported that when keeping glucose concentration lower than $60 \mathrm{mM}$, as the ratio of fatty acid to glucose increased (up to 10:1), the initial rate increased. Excessively high glucose concentration decreased the enzyme activity due to substrate inhibition. Another study indicated the use of supersaturated glucose solution $(50 \mathrm{mM})$ achieved the initial conversion rate of $35 \mu \mathrm{mol} /(\mathrm{min}$. g), which was four times higher than the use of crystalline $\alpha$-glucose (Flores, Naraghi, Engasser, \& Halling, 2002). In our study, although the ratio of 1:1 of lauric acid with glucose system had similar substrates amount with the former study, the high reaction rate $(35 \mu \mathrm{mol} /(\mathrm{min} \cdot \mathrm{g}))$ was not reached. The reasons were that we used different solvent, enzyme amount and reaction temperature, and the glucose saturation concentration was not achieved.

In addition to solvent choice, initial sugar solubility is also be associated with medium hydrophobicity (Pedersen, Wimmer, Emmersen, Degn, \& Pedersen, 2002; Reyes-Duarte, LópezCortés, Ferrer, Plou, \& Ballesteros, 2005). Glucose solubility increased as the chain length of the fatty acid decreased at each substrate ratio. The solubility is also associated with the amount of sugar that was put into the medium, as it increased when the ratio of sugar increased, since they themselves created a more polar environment. Though not measured in our study, previous studies indicated as the esters were being produced, glucose solubility would increase through hydrophobic interaction of glucose-fatty acid ester (Degn \& Zimmermann, 2001; Tsavas, et al., 2002).

The initial conversion rates may or may not relate to the length of the acyl donor, as previously reported. Some studies reported the reaction rate was faster for shorter chain length 
of fatty acid (C4-C12) that were esterified with disaccharide (Pedersen, Wimmer, Emmersen, Degn, \& Pedersen, 2002). Adelhorst, Bjokling, Godtfredsen and Kirk (1990) reported the enzyme showed faster reaction with longer fatty acids (C12-C18) than shorter acids (C8-C10) in solvent free condition. However, Degn, Pedersen, \& Zimmermann, (1999) found that the initial reaction rate was independent within chain length C2-C20 of acyl donors for glucose. Our study also indicated that the initial rate and alkyl chain length was independent. The different observations in literature and our study could be due to the difference in substrate and reaction conditions.

\subsection{Product identification and complete $1 \mathrm{H}$ and $13 \mathrm{C}$ assignment for reactants and products.}

The formation of glucose palmitate, glucose laurate and glucose hexanoate were confirmed by LCMS (data not shown) and NMR techniques. In the HMBC graph (Figure 2) of reaction mixture of glucose and palmitic acid, the sixth protons (4.01 and $4.27 \mathrm{ppm}$ ) of glucose were seen to have interacted with carbonyl carbon indicating the formation of ester bonds. The chemical shifts of H-6 of glucose and $\alpha$-carbon proton of fatty acid in the esters to the higher fields indicated the chemical environment change due to esterification that caused de-shielding effect (Kitagawa, Tokiwa, Fan, Raku, \& Tokiwa, 2000; Pedersen, Wimmer, Emmersen, Degn, \& Pedersen, 2002; Walsh, Bombyk, Wagh, Bingham, \& Berreau, 2009). We had two chemical shifts for the sixth proton in glucose indicating the alpha and beta conformation of the D-glucose (Roslund, Tähtinen, Niemitz, \& Sjöholm, 2008). Similar NMR graph for glucose laurate and glucose hexanoate esters were obtained.

We successfully obtained the purity of $95.50 \%, 98.97 \%$ of glucose palmitate and glucose laurate, respectively. Due to relatively high solubility of glucose hexanoate in both hydrophobic 
and hydrophilic environment, it was not possible to purify the ester by solvent extraction. NMR data for glucose hexanoate was obtained from reaction mixture rather than pure product.

\subsection{Contact angle on product surface}

Due to the low solubility of glucose palmitate in water, it was hard to measure the critical micelle concentration and surface tension; therefore, contact angle was measured for the esters to compare the relative hydrophobicity or wettability. The hydrophobicity is generally positively related to contact angle (Daffonchio, Thaveesri, \& Verstraete, 1995) and reversely related to HLB value (Griffin, 1949). The contact angles and HLB values for glucose palmitate, glucose laurate, SP30, SP50 and PS750 were 98.6 (HLB 8.6), 93.6 (HLB 9.9), 76.9 (HLB 6), 44.8 (HLB 11) and 28.1 (HLB 16) respectively. The contact angles of our products followed the trend: the longer alkyl chain of the fatty acid moiety is, the more hydrophobic of the ester is, the larger the contact angle is. The HLB values for these two products were calculated respectively according to the method of Griffin (1955). The HLB value indicates that both of the esters can perform as emulsifiers and wetting agents for oil-in-water system (value from 7-18, according to Griffin (1946)). Commercial SP50 and PS750 esters may have more function in detergent and solubilizing application because they had higher HLB value (Griffin, 1949). Overall, the larger

the contact angle the ester had, the lower the HLB value they were, except that SP30 had lower HLB value than glucose palmitate but it had lower contact angle than the other.

\subsection{Emulsion stability of esters}

The emulsion stability index (ESI) for esters are shown in Figure 3. Glucose esters were not water-soluble and they stayed on top of aqueous phase; whereas, sucrose esters were 
dispersible but not soluble. Glucose esters demonstrated stabilizing effect compared to control treatment. The ESI increased as the concentration increased for all esters, which indicated lower concentrations of esters did not completely cover the oil surface to prevent creaming, the addition of more esters covered more surface area so the creaming process were retarded. At low concentrations of $0.01 \%$ for glucose palmitate and glucose laurate, the ESI values $(171.4,178.0$ respectively) were slightly higher than control treatment (138.8). At medium concentration of $0.1 \%$, glucose palmitate ESI (315.3) was twice as much as control, whereas glucose laurate ESI (163.4) did not increase compared to $0.01 \%$. At $0.5 \%$, glucose palmitate again showed stronger stabilizing effect (ESI 664.7) than glucose laurate (ESI 460.8). These data show that glucose palmitate had better stabilizing effect than glucose laurate. One reason for this could be the stronger hydrophobic interactions by longer alkyl chains in the molecule with each other and with oil droplets, which can form a more compact structure than glucose laurate (Ferrer, Comelles, Plou, Cruces, Fuentes, Parra, et al., 2002).

For commercial sucrose esters, similarly, the ESI increased as the concentration increased. Compared with glucose esters, the sucrose esters had better stabilizing effect since the ESI were higher than those of in-house glucose esters at every concentration. Particularly, at $0.5 \%$, the ESI were significantly higher $(1351.8,1212.5,1492.3$ for SP30, SP50, PS750 respectively) than glucose esters.

\subsection{Emulsion droplet size distributions}

Droplet distribution and diameter parameters for control, glucose palmitate, glucose laurate, and sucrose esters SP30 are presented in Figure 4 and Table 2 respectively. It was obvious for control and glucose esters that the distribution had undergone from single-modal to bio-modal or tri-modal change during 7-day storage, indicating the size were diverging into 
bigger or smaller. The appearance of the peaks to the right side of the distribution indicated the presence of droplets that have not been completely covered by the surfactants have experienced coalescence (McClement, 2004a). The sucrose esters emulsified systems were relatively stable as the distributions were bio-modal or tri-modal throughout. Only one for the sucrose esters is presented because the distribution of the patterns were similar.

Mean and standard deviation of the droplet diameters for each treatment for 7-day time points are reported in Table 2; for multiple comparison, data were transformed to a natural log scale to fit the normal distribution. For all the diameters, both fixed effects (type of esters and time) had significant effects on change in droplet diameters $(\mathrm{P}<0.05)$. The interaction of treatment and time was also significant $(\mathrm{P}<0.05)$, meaning the diameters changed differently among all the treatments at different times. From $0 \mathrm{~h}$ to $7^{\text {th }}$ day, D[0.1] decreased gradually for control $(5.2 \mu \mathrm{m}$ to $2.0 \mu \mathrm{m})$, glucose palmitate $(1.7 \mu \mathrm{m}$ to $0.3 \mu \mathrm{m})$ and glucose laurate-stabilized emulsions ( $2.0 \mu \mathrm{m}$ to $0.3 \mu \mathrm{m})$, respectively; multiple comparison of log-transformed data indicated that the change was significant $(\mathrm{P}<0.05)$. However, droplet size almost did not change for sucrose esters. This indicated that smaller droplets were decreasing in control and glucose esters and were undergoing coalescence. This can be confirmed by $\mathrm{D}[0.9]$ and volume mean diameter $\mathrm{D}[4,3]$ that the size of droplets for these three esters were increasing. However, they increased differently - for the volume mean diameter, control group experienced the greatest change (from 37.2-74.7 $\mu \mathrm{m}$ ), glucose palmitate stabilized droplet changed from 18.2 um to 32.7 um, glucose laurate stabilized droplet changed from $16.6 \mathrm{um}$ to $47.4 \mathrm{um}$. This indicated that glucose palmitate and glucose laurate generated smaller droplets overall and they had stabilizing effect on droplet size, but could not completely prevent coalescence. Compared with glucose laurate, glucose palmitate is relatively more effective in stabilizing the oil-in-water emulsions. 
The commercial sucrose esters can effectively prevent coalescence, as indicated by no significant changes for diameter parameters over time. Four mechanisms can explain the phenomenon we observed: hydrophobic interaction (Ferrer, et al., 2002), steric stabilization (Nilsson \& Bergenståhl, 2007), adsorption on the interfacial surface, and depletion interaction (McClement, 2004b). Between glucose palmitate and glucose laurate, the former has longer alkyl chain, likely with the stronger hydrophobic interaction with oil droplets resulting in larger area coverage on the droplet to prevent coalescence. Also, the bigger molecule of glucose palmitate has stronger steric hindrance that prevent droplet from aggregating. For sucrose esters, both steric hindrance and adsorption contribute to the better stabilization effect. Sucrose esters has bigger size because the presence of a fructose moiety in addition to glucose, meanwhile the presence of more hydroxyl group made it easier to solubilize in the continuous phase and easier to adsorb at the interface, whereas glucose esters had much lower solubility in the continuous phase, their adsorption at the interface were much slower. Depletion interaction also existed because the excess amount of low-soluble glucose esters in the dispersed phase caused hydrophobic interactions of droplets that promote coalescence.

\section{Conclusion}

Glucose-fatty acid monoesters were successfully synthesized in tert-amyl butanol and DMSO mixture solvent system in lipase catalyzed reactions with high level of conversion. Products were purified with solvent extraction. Synthesized and commercial esters were compared for emulsion capabilities. Glucose esters stabilized oil droplets to some extent, but could not completely prevent coalescence compared to commercial sucrose esters. The relatively smaller sizes of glucose esters and low aqueous solubility can explain their difference of emulsifying property. 


\section{Acknowledgement}

Iowa State University Agriculture Experiment Station and USDA/NIFA multistate

project S1041 partially contributed to the project. We express sincere appreciation to Iowa State

University Chemical Instrumentation Facility staff member Sarah Cady for training and

assistance to interpret the AVIII-600 results included in this publication.

\section{Reference}

Adelhorst, K., Bjokling, F., Godtfredsen, S. E., \& Kirk, O. (1990). Enzyme catalysed preparation of 6-O-acylglucopyranosides. Synthesis(2), 112-115.

Arcos, J., Bernabe, M., \& Otero, C. (1998). Quantitative enzymatic production of 6 - O acylglucose esters. Biotechnology and Bioengineering, 57(5), 505-509.

Crowley, S. V., Desautel, B., Gazi, I., Kelly, A. L., Huppertz, T., \& O’Mahony, J. A. (2015). Rehydration characteristics of milk protein concentrate powders. Journal of Food Engineering, 149, 105-113.

Daffonchio, D., Thaveesri, J., \& Verstraete, W. (1995). Contact angle measurement and cell hydrophobicity of granular sludge from upflow anaerobic sludge bed reactors. Applied and environmental microbiology, 61(10), 3676-3680.

Degn, P., Pedersen, L. H., \& Zimmermann, W. (1999). Lipase-catalysed synthesis of glucose fatty acid esters in tert-butanol. Biotechnology letters, 21(4), 275-280.

Degn, P., \& Zimmermann, W. (2001). Optimization of carbohydrate fatty acid ester synthesis in organic media by a lipase from Candida antarctica. Biotechnology and bioengineering, 74(6), 483-491.

Deleu, M., \& Paquot, M. (2004). From renewable vegetables resources to microorganisms: new trends in surfactants. Comptes Rendus Chimie, 7(6), 641-646.

Desai, J. D., \& Banat, I. M. (1997). Microbial production of surfactants and their commercial potential. Microbiology and Molecular biology reviews, 61(1), 47-64.

Ferrer, M., Comelles, F., Plou, F. J., Cruces, M. A., Fuentes, G., Parra, J. L., \& Ballesteros, A. (2002). Comparative surface activities of di-and trisaccharide fatty acid esters. Langmuir, 18(3), 667-673.

Ferrer, M., Cruces, M. A., Bernabe, M., Ballesteros, A., \& Plou, F. J. (1999). Lipase-catalyzed regioselective acylation of sucrose in two-solvent mixtures. Biotechnology and bioengineering, 65(1), 10-16.

Flores, M. V., Naraghi, K., Engasser, J. M., \& Halling, P. J. (2002). Influence of glucose solubility and dissolution rate on the kinetics of lipase catalyzed synthesis of glucose laurate in 2 - methyl 2 - butanol. Biotechnology and bioengineering, 78(7), 815-821.

Fregapane, G., Sarney, D. B., \& Vulfson, E. N. (1991). Enzymic solvent-free synthesis of sugar acetal fatty acid esters. Enzyme and microbial technology, 13(10), 796-800.

Greek, B. (1991). Sales of detergents growing despite recession. Chemical \& Engineering News, 69(4), 25-\&.

Greek, B. F. (1990). Detergent industry ponders products for new decade. Chemical \& Engineering News, 68(5), 37-\&. 
Griffin, W. C. (1946). Classification of surface-active agents by" HLB". J Soc Cosmetic Chemists, 1, 311-326.

Habulin, M., Šabeder, S., \& Knez, Ž. (2008). Enzymatic synthesis of sugar fatty acid esters in organic solvent and in supercritical carbon dioxide and their antimicrobial activity. The Journal of Supercritical Fluids, 45(3), 338-345.

Hayes, D. G. (2011). LIPIDS-Bioprocessing Methods to Prepare Biobased Surfactants for Pharmaceutical Products. American Pharmaceutical Review, 14(3), 8.

Kitagawa, M., Tokiwa, T., Fan, H., Raku, T., \& Tokiwa, Y. (2000). Transesterification of divinyladipate with glucose at various temperatures by an alkaline protease of Streptomyces sp. Biotechnology letters, 22(10), 879-882.

Lee, S. H., Ha, S. H., Hiep, N. M., Chang, W.-J., \& Koo, Y.-M. (2008). Lipase-catalyzed synthesis of glucose fatty acid ester using ionic liquids mixtures. Journal of biotechnology, 133(4), 486-489.

Ljunger, G., Adlercreutz, P., \& Mattiasson, B. (1994). Lipase catalyzed acylation of glucose. Biotechnology letters, 16(11), 1167-1172.

McClement, D.J. (2004a). Food Emulsion. (2 nd.). Boca Raton: CRC Press, (Chapter 1).

McClements, D. J. (2004b). Food emulsions: principles, practice and techniques (2nd ed.) Boca Raton: CRC Press. (Chapter 3).

Mitsubishi-Kagaku Food Corporation. (2016). Available from <http://www.mfc.co.jp/english/infor.htm>. Aceessed 2.21.16.

Martin-Arjol, I., Isbell, T. A., \& Manresa, A. (2015). Mono-Estolide Synthesis from trans-8Hydroxy-Fatty Acids by Lipases in Solvent-Free Media and Their Physical Properties. Journal of the American Oil Chemists' Society, 92(8), 1125-1141.

Nilsson, L., \& Bergenståhl, B. (2007). Emulsification and adsorption properties of hydrophobically modified potato and barley starch. Journal of agricultural and food chemistry, 55(4), 1469-1474.

Park, S., \& Kazlauskas, R. J. (2001). Improved preparation and use of room-temperature ionic liquids in lipase-catalyzed enantio-and regioselective acylations. The Journal of organic chemistry, 66(25), 8395-8401.

Pearce, K. N., \& Kinsella, J. E. (1978). Emulsifying properties of proteins: evaluation of a turbidimetric technique. Journal of Agricultural and Food Chemistry, 26(3), 716-723.

Pedersen, N. R., Wimmer, R., Emmersen, J., Degn, P., \& Pedersen, L. H. (2002). Effect of fatty acid chain length on initial reaction rates and regioselectivity of lipase-catalysed esterification of disaccharides. Carbohydrate Research, 337(13), 1179-1184.

Plat, T., \& Linhardt, R. J. (2001). Syntheses and applications of sucrose-based esters. Journal of Surfactants and Detergents, 4(4), 415-421.

Pohnlein, M., Ulrich, J., Kirschhofer, F., Nusser, M., Muhle-Goll, C., Kannengiesser, B., Brenner-Weiss, G., Luy, B., Liese, A., Syldatk, C., \& Hausmann, R. (2015). Lipasecatalyzed synthesis of glucose-6-O-hexanoate in deep eutectic solvents. European Journal of Lipid Science and Technology, 117(2), 161-166.

Reyes-Duarte, D., López-Cortés, N., Ferrer, M., Plou, F. J., \& Ballesteros, A. (2005). Parameters affecting productivity in the lipase-catalysed synthesis of sucrose palmitate. Biocatalysis and Biotransformation, 23(1), 19-27.

Rich, J. O., Bedell, B. A., \& Dordick, J. S. (1995). Controlling enzyme-catalyzed regioselectivity in sugar ester synthesis. Biotechnology and Bioengineering, 45(5), 426-434. 
Roslund, M. U., Tähtinen, P., Niemitz, M., \& Sjöholm, R. (2008). Complete assignments of the 1 $\mathrm{H}$ and $13 \mathrm{C}$ chemical shifts and $\mathrm{J} \mathrm{H}, \mathrm{H}$ coupling constants in NMR spectra of dglucopyranose and all d-glucopyranosyl-d-glucopyranosides. Carbohydrate research, 343(1), 101-112.

Schöfer, S. H., Kaftzik, N., Wasserscheid, P., \& Kragl, U. (2001). Enzyme catalysis in ionic liquids: lipase catalysed kinetic resolution of 1-phenylethanol with improved enantioselectivity. Chemical Communications(5), 425-426.

Tsavas, P., Polydorou, S., Faflia, I., Voutsas, E. C., Tassios, D., Flores, M. V., Naraghi, K., Halling, P. J., Chamouleau, F., \& Ghoul, M. (2002). Solubility of glucose in mixtures containing 2-methyl-2-butanol, dimethyl sulfoxide, acids, esters, and water. Journal of Chemical \& Engineering Data, 47(4), 807-810.

Van Rantwijk, F., Woudenberg-van Oosterom, M., \& Sheldon, R. (1999). Glycosidase-catalysed synthesis of alkyl glycosides. Journal of Molecular Catalysis B: Enzymatic, 6(6), 511532.

Walsh, M. K., Bombyk, R. A., Wagh, A., Bingham, A., \& Berreau, L. M. (2009). Synthesis of lactose monolaurate as influenced by various lipases and solvents. Journal of Molecular Catalysis B: Enzymatic, 60(3), 171-177.

Ward, O. P., Fang, J., \& Li, Z. (1997). Lipase-catalyzed synthesis of a sugar ester containing arachidonic acid. Enzyme and microbial technology, 20(1), 52-56.

Wei, D., Yu, Y., Song, Q., \& Su, W. (2003). Enzymatic synthesis of ethyl-glucoside monooleate with lipase in solvent-free medium. Biocatalysis and Biotransformation, 21(3), 135-139.

Zaidan, U. H., Abdul Rahman, M. B., Othman, S. S., Basri, M., Abdulmalek, E., Abdul Rahman, R. N. Z. R., \& Salleh, A. B. (2012). Biocatalytic production of lactose ester catalysed by mica-based immobilised lipase. Food Chemistry, 131(1), 199-205. 


\section{List of Tables}

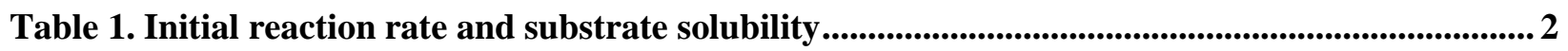

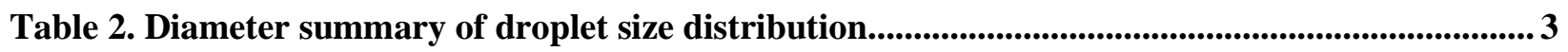


Table 1 Initial reaction rate $\left(\mu \mathrm{mol} / \mathrm{min}^{*} \mathrm{~g}\right)$ and substrate solubility $(\mathrm{mM})$

\begin{tabular}{|c|c|c|c|c|c|c|c|c|c|}
\hline $\begin{array}{c}\text { Ratio of } \\
\text { fatty } \\
\text { acid/glucose }\end{array}$ & $\begin{array}{c}\text { PA initial } \\
\text { conversion rate } \\
(\mu \mathrm{mol} /(\mathrm{min} \cdot \\
\mathrm{g}))\end{array}$ & $\begin{array}{c}\text { Initial } \\
\text { sugar } \\
\text { solubility } \\
(\mathrm{mM})\end{array}$ & $\begin{array}{c}\text { PA } \\
\text { concentration } \\
(\mathrm{mM})\end{array}$ & $\begin{array}{c}\text { LA initial } \\
\text { conversion rate } \\
(\mu \mathrm{mol} /(\mathrm{min} \cdot \\
\mathrm{g}))\end{array}$ & $\begin{array}{c}\text { Initial } \\
\text { sugar } \\
\text { solubility } \\
(\mathrm{mM})\end{array}$ & $\begin{array}{c}\text { LA } \\
\text { concentration } \\
(\mathrm{mM})\end{array}$ & $\begin{array}{c}\text { HA initial } \\
\text { conversion rate } \\
(\mu \mathrm{mol} /(\min \\
\cdot \mathrm{g}))\end{array}$ & $\begin{array}{c}\text { Initial sugar } \\
\text { solubility }(\mathrm{mM})\end{array}$ & $\begin{array}{c}\text { HA } \\
\text { concentration } \\
(\mathrm{mM})\end{array}$ \\
\hline $3: 1$ & $9.6^{\mathrm{a}}$ & $16.9^{c}$ & $243.7^{\mathrm{a}}$ & $7.2^{\mathrm{a}}$ & $21.1^{b}$ & $259.6^{\mathrm{a}}$ & $11.8^{\mathrm{a}}$ & $26.2^{\mathrm{a}}$ & $235.2^{\mathrm{a}}$ \\
\hline $2: 1$ & $4.8^{b}$ & $18.3^{\mathrm{bc}}$ & $158.0^{\mathrm{b}}$ & $5.3^{\mathrm{a}}$ & $22.5^{b}$ & $178.3^{b}$ & $3.8^{b}$ & $22.8^{a}$ & $146.5^{b}$ \\
\hline $1: 1$ & $3.3^{b}$ & $21.0^{b}$ & $74.3^{c}$ & $2.2^{b}$ & $21.6^{b}$ & $103.8^{\mathrm{c}}$ & $2.3^{b}$ & $28.1^{\mathrm{a}}$ & $75.5^{c}$ \\
\hline $1: 3$ & $5.2^{\mathrm{ab}}$ & $28.2^{\mathrm{a}}$ & $72.9^{c}$ & $2.6^{\mathrm{b}}$ & $33.6^{\mathrm{a}}$ & $103.6^{\mathrm{c}}$ & $2.7^{\mathrm{b}}$ & $30.5^{\mathrm{a}}$ & $74.4^{\mathrm{c}}$ \\
\hline
\end{tabular}

PA- palmitic acid, LA- lauric acid, HA- hexanoic acid. Different letters indicate significantly difference in a row $(\mathrm{P}<0.05)$. 
Table 2 Diameter summary of droplet size distribution

\begin{tabular}{|c|c|c|c|c|c|c|c|c|c|c|}
\hline & \multicolumn{5}{|c|}{$\mathrm{D}[0.1]$} & \multicolumn{5}{|c|}{$\mathrm{D}[0.5]$} \\
\hline & $\mathrm{Oh}$ & $6 \mathrm{~h}$ & $24 \mathrm{~h}$ & $3 d$ & $7 \mathrm{~d}$ & $\mathrm{Oh}$ & $6 \mathrm{~h}$ & $24 \mathrm{~h}$ & $3 \mathrm{~d}$ & $7 d$ \\
\hline Control & $5.2 \pm 1.2$ & $1.2 \pm 0.3$ & $1.2 \pm 0.1$ & $2.3 \pm 1.2$ & $2.0 \pm 2.0$ & $26.8 \pm 4.6$ & $10.4 \pm 6.5$ & $58.0 \pm 28.3$ & $65.5 \pm 41.9$ & $17.1 \pm 2.2$ \\
\hline GP & $1.7 \pm 0.1$ & $0.6 \pm 0.1$ & $0.6 \pm 0.0$ & $0.4 \pm 0.1$ & $0.3 \pm 0.0$ & $6.6 \pm 0.5$ & $2.4 \pm 0.1$ & $2.5 \pm 0.1$ & $2.8 \pm 0.3$ & $2.6 \pm 0.8$ \\
\hline GL & $2.0 \pm 0.3$ & $0.4 \pm 0.1$ & $0.4 \pm 0.1$ & $0.4 \pm 0.0$ & $0.3 \pm 0.0$ & $9.8 \pm 0.8$ & $2.4 \pm 0.3$ & $2.6 \pm 1.0$ & $5.9 \pm 4.2$ & $3.1 \pm 1.2$ \\
\hline SP30 & $0.4 \pm 0.1$ & $0.3 \pm 0.1$ & $0.4 \pm 0.0$ & $0.3 \pm 0.1$ & $0.3 \pm 0.0$ & $6.4 \pm 1.8$ & $4.7 \pm 2.4$ & $8.3 \pm 2.7$ & $6.9 \pm 2.3$ & $7.1 \pm 2.0$ \\
\hline SP50 & $0.3 \pm 0.1$ & $0.3 \pm 0.0$ & $0.3 \pm 0.0$ & $0.2 \pm 0.0$ & $0.3 \pm 0.1$ & $5.4 \pm 0.8$ & $2.8 \pm 1.4$ & $4.3 \pm 2.1$ & $2.1 \pm 1.4$ & $4.5 \pm 2.8$ \\
\hline PS750 & $0.5 \pm 0.2$ & $0.3 \pm 0.0$ & $0.3 \pm 0.1$ & $0.3 \pm 0.0$ & $0.2 \pm 0.0$ & $4.7 \pm 2.1$ & $1.3 \pm 0.4$ & $4.5 \pm 1.4$ & $8.1 \pm 3.5$ & $4.1 \pm 1.0$ \\
\hline
\end{tabular}

\begin{tabular}{|c|c|c|c|c|c|c|c|c|c|c|}
\hline & \multicolumn{5}{|c|}{$\mathrm{D}[0.9]$} & \multicolumn{5}{|c|}{$\mathrm{D}[4,3]$} \\
\hline & $\mathrm{Oh}$ & $6 \mathrm{~h}$ & $24 \mathrm{~h}$ & $3 d$ & $7 d$ & $\mathrm{Oh}$ & $6 \mathrm{~h}$ & $24 \mathrm{~h}$ & $3 d$ & $7 d$ \\
\hline Control & $83.2 \pm 15.3$ & $201.0 \pm 3.6$ & $232.0 \pm 24.1$ & $314.1 \pm 91.4$ & $210.7 \pm 55.3$ & $37.2 \pm 6.8$ & $58.5 \pm 6.7$ & $94.6 \pm 17.3$ & $124.1 \pm 34.2$ & $74.7 \pm 17.5$ \\
\hline GP & $34.1 \pm 4.1$ & $20.6 \pm 22.1$ & $148.5 \pm 93.5$ & $91.3 \pm 23.6$ & $99.5 \pm 96.7$ & $18.2 \pm 4.8$ & $17.8 \pm 6.4$ & $42.3 \pm 29.2$ & $23.7 \pm 5.8$ & $32.7 \pm 30.4$ \\
\hline GL & $36.8 \pm 2.8$ & $35.5 \pm 41.5$ & $117.6 \pm 30.0$ & $172.5 \pm 17.0$ & $160.5 \pm 34.2$ & $16.6 \pm 1.5$ & $21.7 \pm 10.1$ & $32.5 \pm 9.2$ & $57.2 \pm 10.6$ & $47.4 \pm 12.3$ \\
\hline SP30 & $23.2 \pm 4.0$ & $26.1 \pm 5.6$ & $30.9 \pm 4.8$ & $24.0 \pm 6.6$ & $25.9 \pm 3.1$ & $8.1 \pm 1.6$ & $5.2 \pm 3.3$ & $6.9 \pm 2.0$ & $5.5 \pm 5.0$ & $6.4 \pm 5.9$ \\
\hline SP50 & $19.3 \pm 5.1$ & $12.9 \pm 6.0$ & $17.4 \pm 0.6$ & $15.3 \pm 1.6$ & $15.2 \pm 1.6$ & $10.3 \pm 1.7$ & $11.1 \pm 2.0$ & $17.7 \pm 0.8$ & $12.0 \pm 0.8$ & $17.0 \pm 1.6$ \\
\hline PS750 & $24.4 \pm 7.6$ & $22.5 \pm 6.8$ & $29.8 \pm 3.1$ & $64.1 \pm 57.2$ & $34.5 \pm 10.1$ & $10.1 \pm 4.8$ & $6.6 \pm 2.4$ & $10.7 \pm 1.0$ & $21.9 \pm 17.9$ & $12.9 \pm 3.9$ \\
\hline
\end{tabular}

Mean value and standard deviation of diameters are shown in the table. For data analysis, data were transformed to a log scale to fit a normal distribution. 


\section{List of Figures}

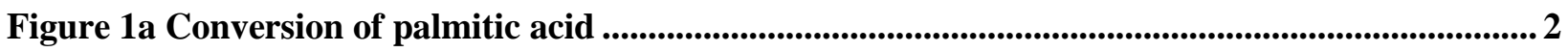

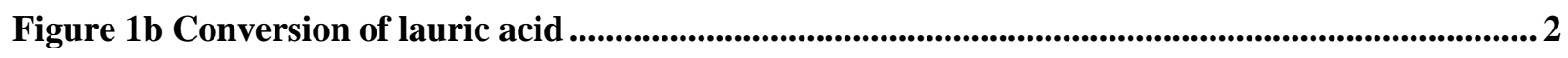

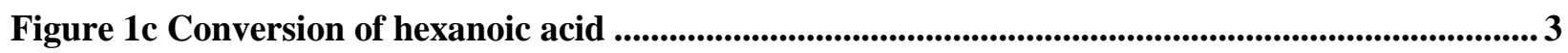

Figure 2 Heteronuclear multiple bond correlation (HMBC) of reaction mixture of palmitic acid

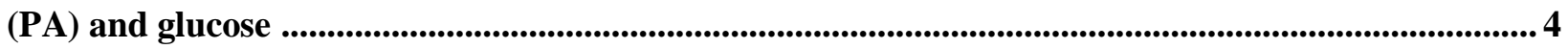

Figure 3 Emulsion stability index of glucose esters and sucrose esters ............................................5

Figure 4a Droplet size distribution of emulsions of control treatment .................................................... 6

Figure 4b Droplet size distribution of emulsions of glucose palmitate..............................................6 6

Figure 4c Droplet size distribution of emulsions of glucose laurate ...................................................... 7

Figure 4c Droplet size distribution of emulsions of sucrose ester SP30 .......................................... 7 


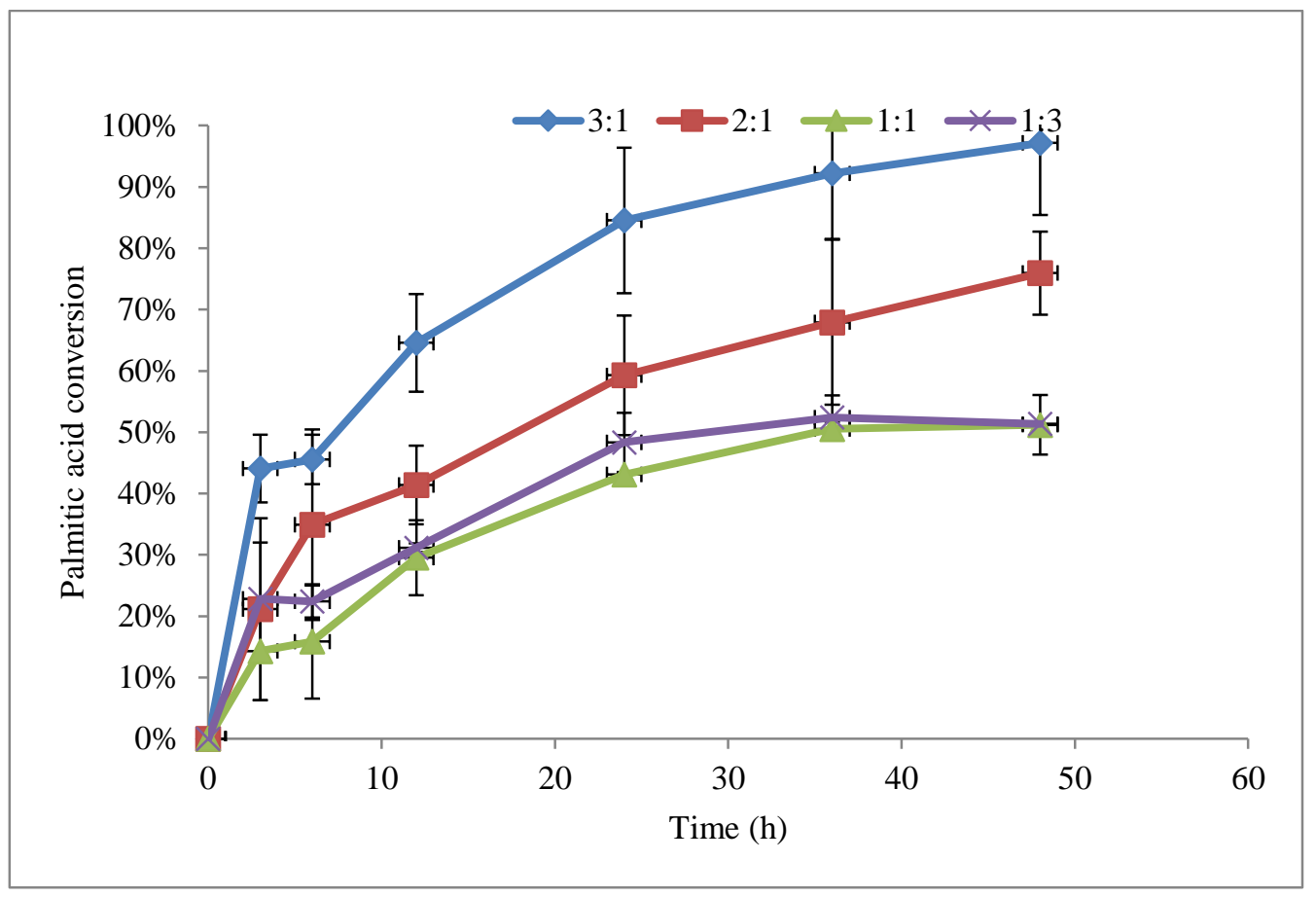

a

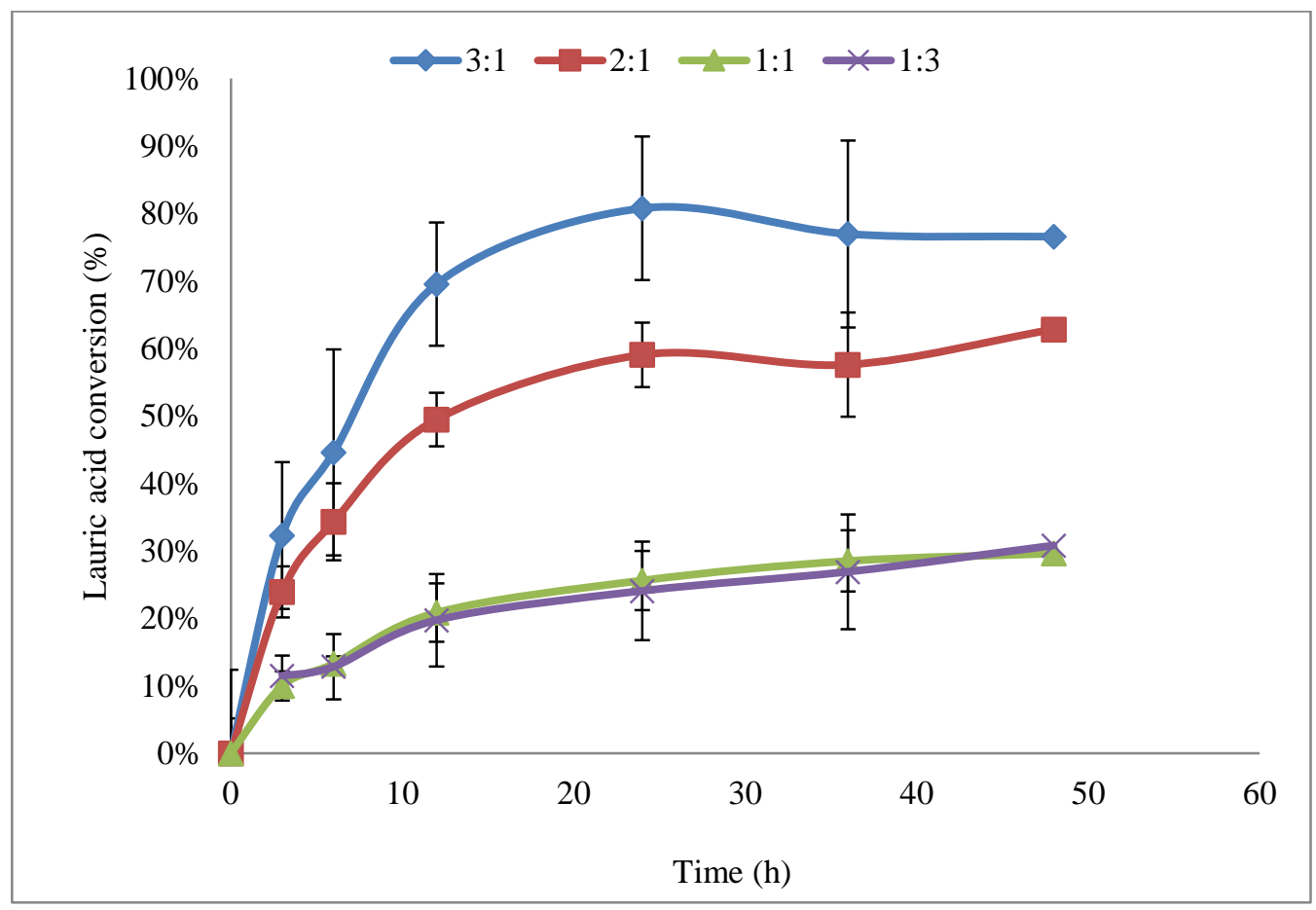

b 


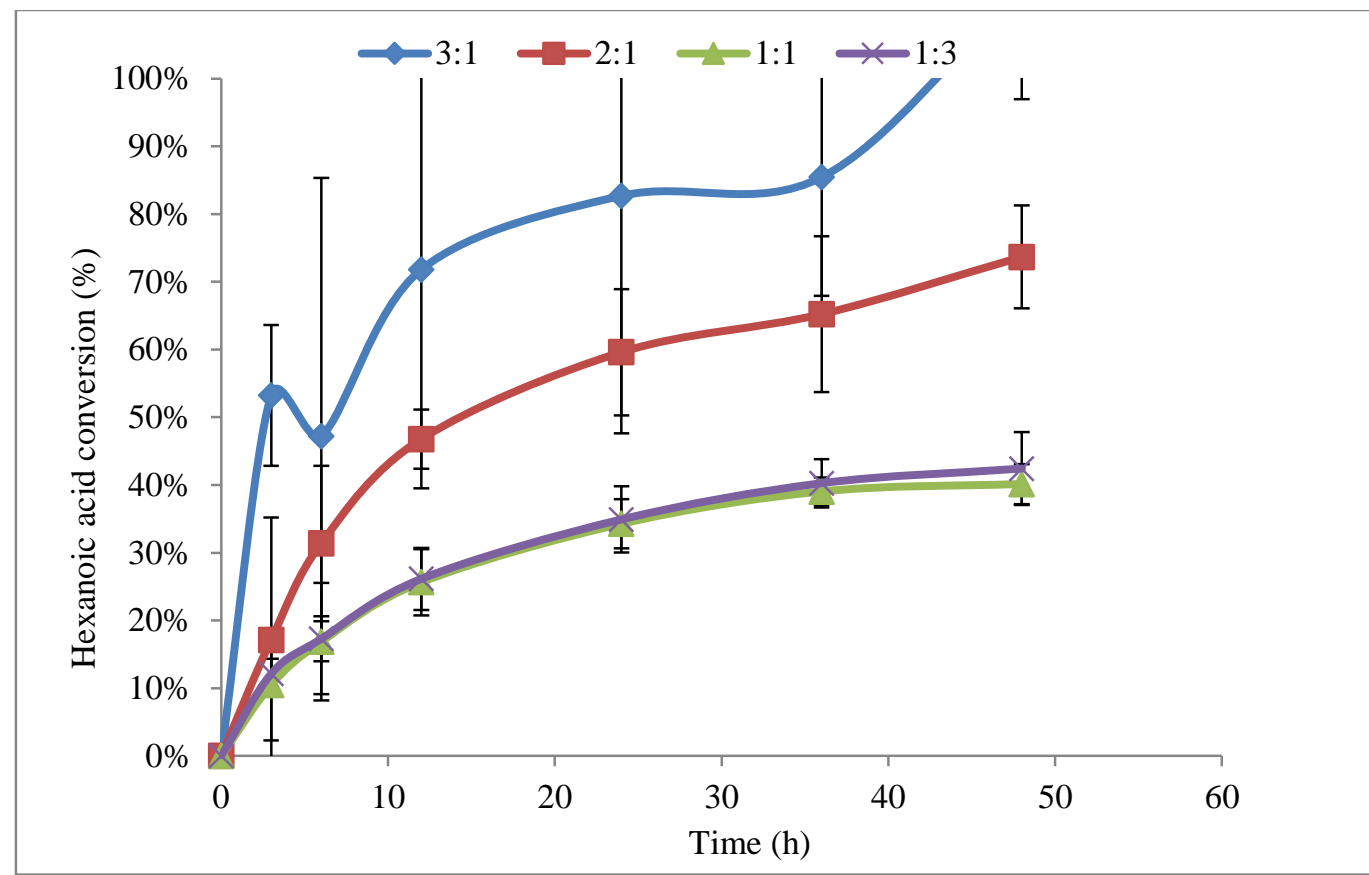

c

Fig 1. Conversion percentage of palmitic acid (a), lauric acid (b) and hexanoic acid (c) during 48 hours. Lines with diamond, square, triangle and cross represents molar ratio of 3:1, 2:1, 1:1 and 1:3 of fatty acid/glucose respectively. Standard deviations were shown. 


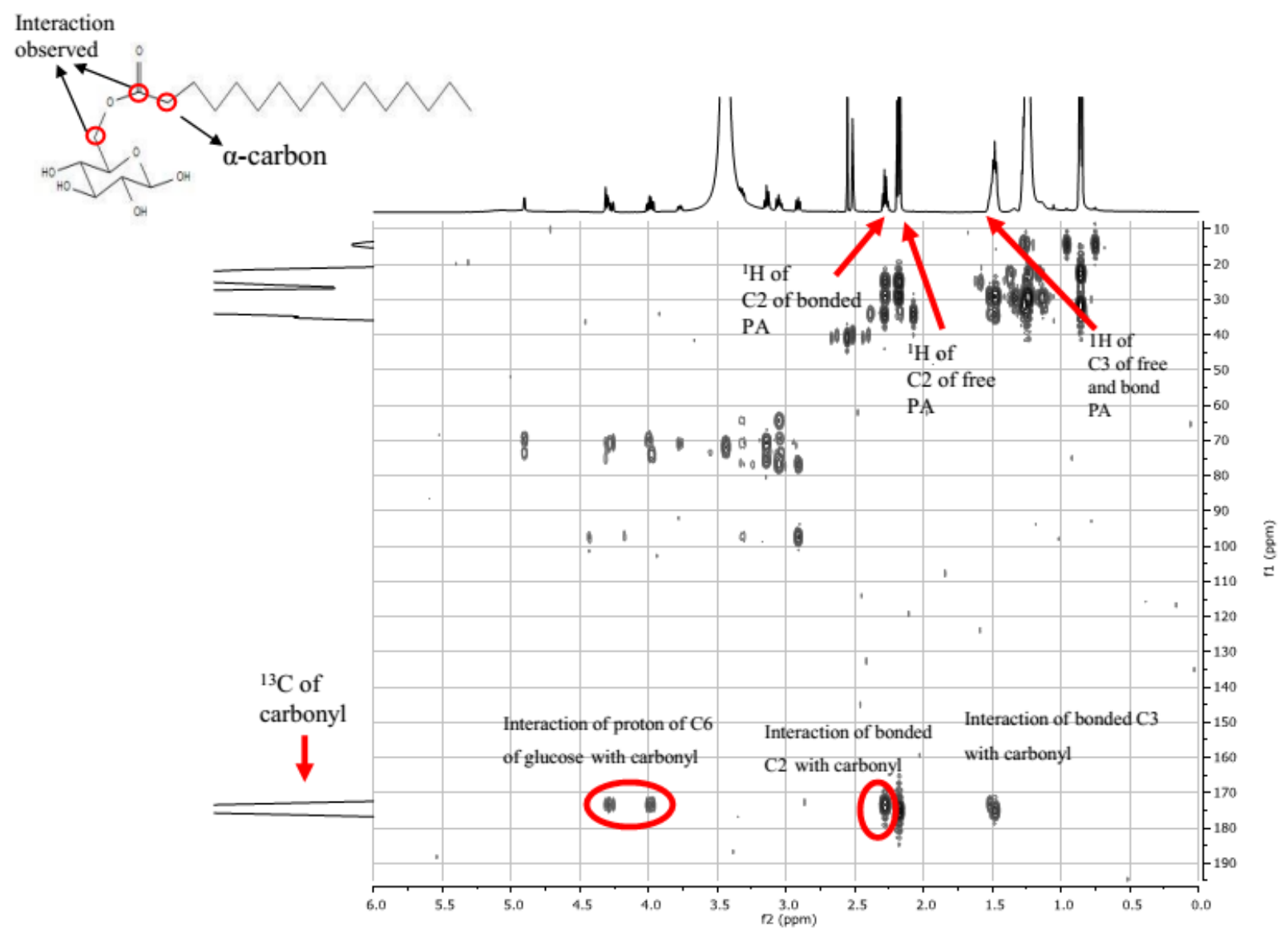

Fig 2. Heteronuclear multiple bond correlation (HMBC) of reaction mixture of palmitic acid (PA) and glucose. The horizontal and vertical axis indicate ${ }^{1} \mathrm{H}$ proton and ${ }^{13} \mathrm{C}$ chemical shift $(\mathrm{ppm})$ respectively. The interaction of proton of $\mathrm{C} 6$ of glucose ring with the carbonyl carbon demonstrated ester bond has been formed. The ester bond also caused the $\alpha$-carbon (the one next to the carbonyl carbon) chemical shift to the higher field. 


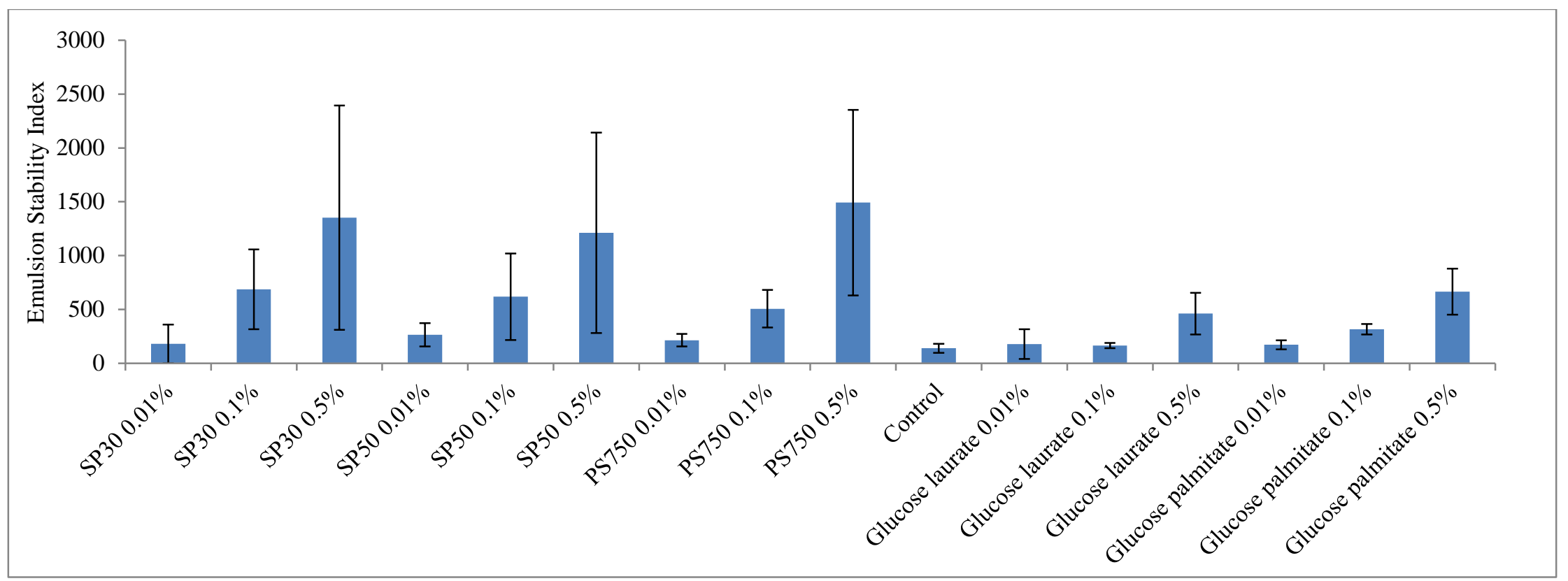

Fig 3. Emulsion stability index of glucose esters and sucrose esters. Mean value and standard deviation are shown. 


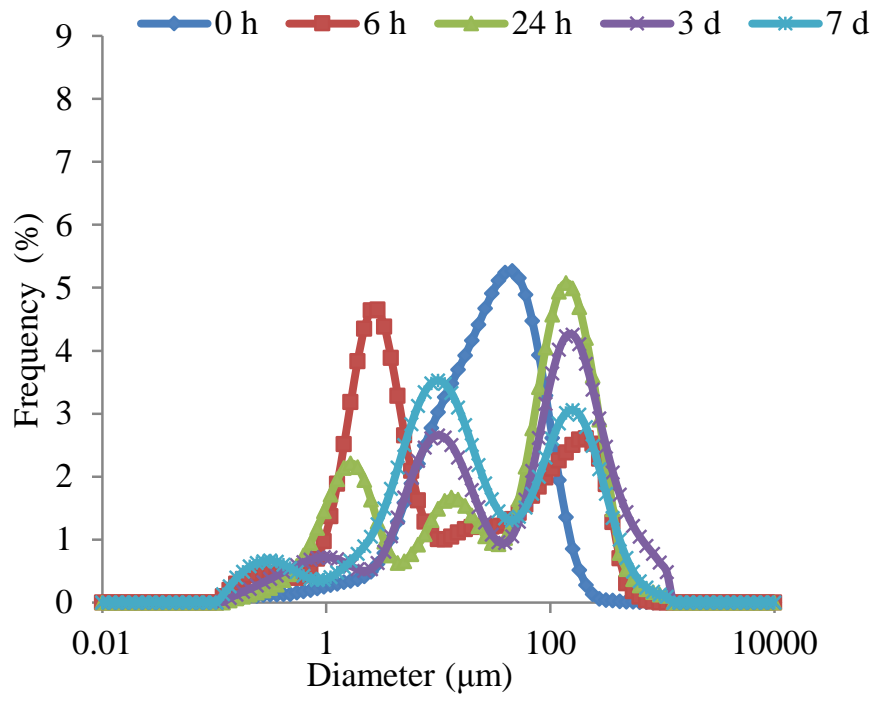

a

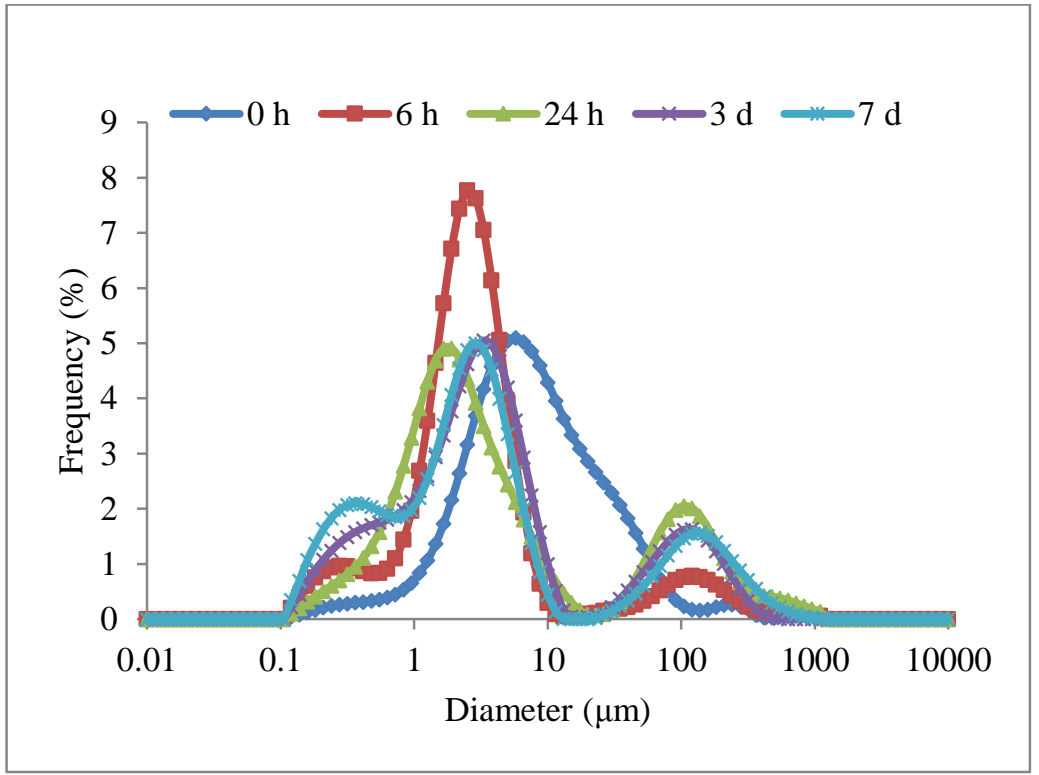

b 


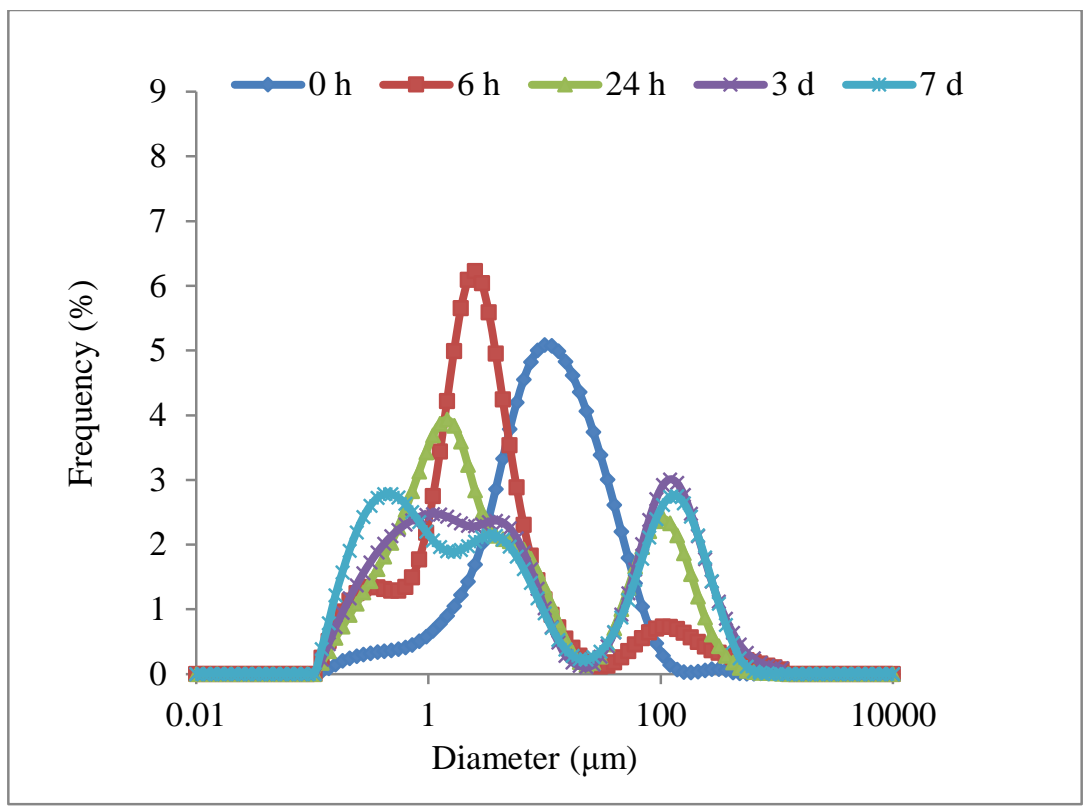

$\mathrm{c}$

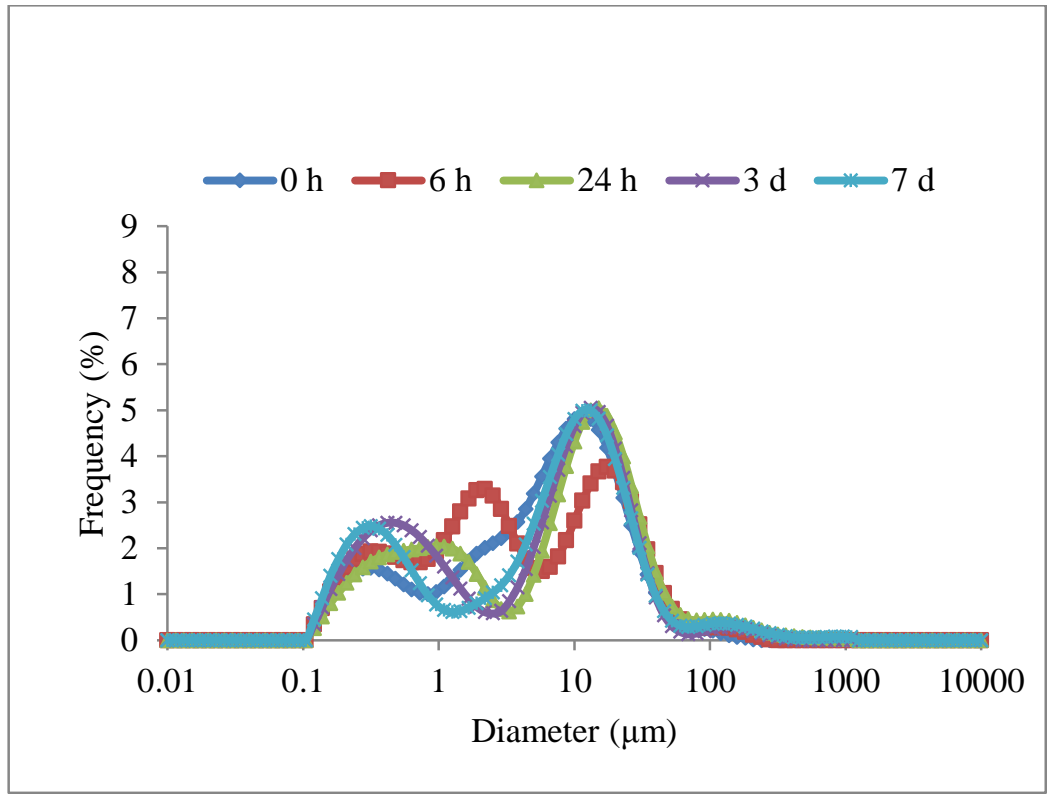

d

Fig 4. Droplet size distribution of emulsions of control treatment (a), glucose palmitate (b), glucose laurate (c), sucrose ester SP30 (d) at $0 \mathrm{~h}, 6^{\text {th }} \mathrm{h}, 24^{\text {th }} \mathrm{h}, 3^{\text {rd }}$ day, $7^{\text {th }}$ day. 